\title{
Mudanças na Estrutura do Comércio Exterior Brasileiro: Uma Análise sob a Ótica da Teoria de Heckscher-Ohlin •
}

\author{
Álvaro Barrantes Hidalgo \\ Professor e Pesquisador - Universidade Federal de Pernambuco (PIMES /UFPE) \\ Endereço para contato: Av. dos Economistas s/n - Cidade Universitária - Recife - PE \\ CEP: 50670-901 - E-mail: abarrantes@uol.com.br
}

\author{
Paulo Ricardo Feistel \\ Professor - Universidade Federal de Santa Maria \\ Endereço para contato: Rua Floriano Peixoto, 1750, sala 611 - Centro - Santa Maria - RS \\ CEP: 97015-372- E-mail: prfeistel@yahoo.com.br
}

Recebido em 06 de outubro de 2011 . Aceito em 25 de novembro de 2012.

\begin{abstract}
Resumo
O objetivo deste trabalho é analisar as mudanças ocorridas na estrutura do comércio exterior brasileiro, após a abertura comercial, em termos de uso dos recursos produtivos disponíveis. A análise é realizada com base na teoria das proporções de fatores, na versão de modelo de três fatores: trabalho, recursos naturais e capital. Utilizando a técnica de insumo-produto, o conteúdo dos fatores produtivos no comércio é mensurado, enquanto é analisada a tendência de longo prazo de especialização da economia brasileira em termos das vantagens comparativas, segundo a teoria de Heckscher-Ohlin. Os resultados obtidos mostram uma tendência de longo prazo de aumento de participação dos produtos intensivos em recursos naturais, além de queda de participação dos produtos intensivos em capital e trabalho na pauta de exportações brasileiras. Por outro lado, no que se refere às importações, estas mostram uma inequívoca tendência de crescente participação de produtos intensivos em capital e uma queda de participação de produtos intensivos em recursos naturais, portanto condizentes com os preceitos das vantagens comparativas de Heckscher-Ohlin.
\end{abstract}

\section{Palavras-Chave}

abertura comercial, vantagens comparativas, Brasil

\begin{abstract}
The objective of this study is to analyze the changes in the Brazilian foreign trade structure after the liberalization trade in terms of use of the available productive resources. The analysis is performed based on the factors proportions theory, in model of three

- Versão anterior deste trabalho foi apresentada no $38^{\circ}$ Encontro Nacional de Economia da ANPEC realizado em Salvador, BA, dezembro de 2010. Os autores agradecem comentários e sugestões recebidos de parecerista anônimo que contribuíram muito para o aprimoramento deste artigo; erros e omissões remanescentes são, naturalmente, de inteira responsabilidade dos autores.
\end{abstract}


factors: labor, natural resources and capital. Using the technique of input-output is measured the content of the trade productive factors while it is analyzed the long-term trend tendencies of Brazilian economic specialization in comparatives advantages terms according to Heckscher-Ohlin theory. The results show a long-term trend of increased participation of resource-intensive products beyond a decrease in the participation of the intensive products in capital and labor in Brazilian exports. On the other hand as they relate to imports, these show a clear trend in the increasing of intensive products in capital and a decrease in the participation of intensive products in natural resources, therefore consistent with the principles of comparative advantages of Heckscher-Ohlin.

\section{Keywords}

trade liberalization, comparative advantages, Brazil

\section{JEL Classification}

F14

\section{Introdução}

$\mathrm{Na}$ última década as exportações brasileiras apresentaram um crescimento significativo e uma mudança na sua estrutura. Esse crescimento e essa mudança verificada na estrutura estão relacionados ao processo de crescimento econômico, à expansão do comércio mundial e às estratégias comerciais que foram seguidas pela economia brasileira no passado. A partir do fim da década de 1980, os formuladores da política econômica brasileira começaram a introduzir algumas medidas de livre comércio, a fim de tornar a economia brasileira mais competitiva e moderna.

Esperava-se que todo esse conjunto de medidas de abertura comercial levasse a uma melhoria na eficiência da economia nacional, promovendo uma melhor alocação intersetorial de recursos, criando as bases para uma inserção mais competitiva na economia internacional. Desse modo, a abertura da economia pretendia promover uma mudança em relação ao passado e integrar a economia brasileira na globalização, em que as atividades menos competitivas deveriam ser substituídas por outras de maior produtividade.

Paralelamente nessa época, o fenômeno da globalização e a formação dos blocos comerciais foram intensificados. Esse processo procurava eliminar as barreiras intrarregionais à livre mobilidade de bens, serviços e capitais, criando um mercado ampliado que permitisse 
uma maior complementaridade das economias nacionais, o aumento do comércio e o incremento da capacidade competitiva baseada nas vantagens naturais de cada país.

As medidas de política comercial, implementadas nacional e internacionalmente, tinham sólido respaldo nos princípios teóricos do comércio internacional, os quais mostram os benefícios para os países da especialização, da divisão internacional do trabalho e do livre comércio.

Após duas décadas de experiência com o novo sistema de comércio internacional, os dados mostram que de fato houve uma expansão significativa do comércio. Segundo dados da Organização Mundial do Comércio (OMC), durante a década dos noventa, as exportações mundiais cresceram a uma taxa média de $6,7 \%$ ao ano. Ao longo da década seguinte, 2000 a 2008, as exportações mundiais tiveram uma expansão média da ordem de $9,7 \%$ ao ano. No que se refere às exportações brasileiras, estas tiveram durante a década dos noventa uma expansão média da ordem de $5,7 \%$ ao ano, passando para 17,3 $\%$ ao ano durante o período 2000 a $2008 .{ }^{1}$

Paralelamente à expansão do comércio houve, e está acontecendo, uma mudança não apenas na estrutura do comércio exterior brasileiro, mas também na direção dos fluxos comerciais, a exemplo do comércio Brasil-China, que se está tornando cada vez mais importante. Quanto à estrutura, as exportações brasileiras de primários vêm crescendo mais que os manufaturados, sendo este fato visto com preocupação por parte de alguns críticos. ${ }^{2}$

Diante desse contexto, o objetivo deste trabalho consiste em analisar as mudanças acontecidas na estrutura do comércio exterior brasileiro

1 A expansão das exportações permitiu a geração de significativos superávits na balança comercial brasileira. Por sua vez, os bons resultados na balança comercial contribuíram para que o governo pagasse parte de sua dívida externa, aumentasse as reservas internacionais e reduzisse a vulnerabilidade externa do país.

2 Argumenta-se que os bens primários têm baixo valor adicionado, baixo conteúdo tecnológico, as receitas de exportação estão sujeitas à instabilidade, além de ser lembrado ainda o velho problema dos termos de troca. Alguns críticos alegam que os primários são bens sobre os quais há pouco controle não apenas sobre os preços, mas também sobre as quantidades a serem vendidas. Outros argumentam, porém, que na economia internacional há muitos exemplos de economias desenvolvidas a partir da exportação de primários, a exemplo da Austrália, Canadá e mais recentemente o Chile. Sobre a questão tecnológica é argumentado que existe sim muita tecnologia embutida em alguns bens primários, como é o caso da tecnologia na produção das carnes, fruto de muitas pesquisas e avanços na genética. 
após a abertura comercial, em termos de uso dos recursos produtivos na economia brasileira e de aproveitamento ou não de vantagens comparativas nos moldes da teoria das proporções de fatores de Heckscher-Ohlin. ${ }^{3}$

Pretende-se mostrar que a mudança não é recente, que ela vem acontecendo desde há alguns anos, e que obedece a um processo natural de aproveitamento de vantagens naturais do país diante de um comércio internacional cada vez mais livre. O estudo dessa questão é relevante não apenas para o entendimento das mudanças no comércio exterior brasileiro, mas também para a formulação de políticas adequadas de comércio exterior. Dada a crescente importância dos produtos primários na pauta de exportações brasileiras, a metodologia que será utilizada pressupõe o uso no processo produtivo não apenas de trabalho e capital, mas também de recursos naturais. A generalização da teoria de Heckscher-Ohlin para o caso de três fatores é possível desde que seja admitida também a existência de pelo menos igual número de bens na economia. Por outro lado a análise empírica da teoria com três fatores é facilitada utilizando o método do "triângulo de dotações", desenvolvido por Leamer. ${ }^{4}$ Dessa forma, o trabalho pretende também contribuir na verificação empírica da teoria do comércio de Heckscher-Ohlin com três fatores de produção para o Brasil, questão esta pouco estudada na literatura.

A fim de atingir os objetivos, o artigo está dividido em cinco seções, além desta primeira. $\mathrm{Na}$ seção dois apresentaremos uma revisão da literatura sobre evidências empíricas da teoria de Heckscher-Ohlin para o Brasil. Na seção três apresentaremos o método que será utilizado a fim de conhecer melhor o uso dos recursos produtivos no comércio exterior brasileiro. Na literatura sobre comércio exterior geralmente parte-se da premissa de que o Brasil é relativamente mais bem dotado de recursos naturais do que de trabalho e capital, sendo este último fator visto como o mais escasso no país. A seção quatro

3 Essa teoria é conhecida também como teoria neoclássica do comércio internacional e defende que um país exportará (importará) bens intensivos no fator relativamente abundante (escasso) nesse país. Existe na literatura outra versão da teoria das vantagens comparativas, a versão clássica, baseada na produtividade do trabalho que não será analisada neste trabalho. A versão clássica, conhecida também como teoria ricardiana do comércio internacional, defende que um país exportará (importará) produtos cujo fator trabalho tiver maior (menor) produtividade.

4 Sobre a generalização da teoria de Heckscher-Ohlin para o caso de mais de dois fatores, ver Samuelson (1953-1954), Kemp (1969) e Ethier (1984). O método do "triângulo de dotações" foi desenvolvido por Leamer (1987) e permite a análise gráfica do modelo de comércio com três fatores de produção. 
será dedicada a examinar essa questão. Na seção cinco apresentaremos a análise dos resultados que foram obtidos, mostrando a evolução do uso dos recursos produtivos e a especialização do comércio exterior brasileiro no período após a abertura comercial. Finalmente, na seção seis apresentaremos as conclusões do trabalho.

\section{Evidências Empíricas da Teoria de Heckscher-Ohlin no Comércio Exterior Brasileiro: Revisão da Literatura}

A teoria do comércio internacional de Heckscher-Ohlin (H-O) tem sido objeto de diversos testes empíricos para a economia brasileira. O objetivo desta seção é apresentar uma revisão dos principais trabalhos realizados sobre o assunto. Conforme será visto, nem sempre os testes empíricos realizados conseguiram verificar a teoria de $\mathrm{H}-\mathrm{O}$ para o Brasil, principalmente quando se utiliza a abordagem tradicional que considera o capital e o trabalho como sendo os fatores de produção. Diferentemente os trabalhos realizados para o Brasil sob a ótica da qualificação da mão de obra tiveram mais sucesso e geralmente apontam para resultados não paradoxais. Os primeiros testes empíricos remontam aos anos setenta do século passado. Um primeiro trabalho que pode ser considerado é Tyler (1970), que examinou a intensidade de capital das exportações industriais brasileiras.

O autor utilizou a relação valor adicionado por trabalhador como medida da intensidade de capital. A intensidade fatorial em cada setor foi calculada, ponderando o valor adicionado por trabalhador em cada indústria, pela participação relativa dessa indústria na exportação total de produtos manufaturados. $\mathrm{O}$ autor encontrou que a média nacional do valor adicionado por trabalhador para 1965 era inferior ao valor adicionado das exportações industriais. Concluise, com base nessas informações, que as indústrias brasileiras que tem seus produtos exportados eram, em média, operadas em regime de capital intensivo, aplicando-se, segundo o autor, o paradoxo de Leontief ao Brasil; ver a respeito Leontief (1953). Posteriormente, Tyler (1972) testou a versão ampliada da teoria de H-O, considerando o trabalho especializado na oferta de fatores determinantes do comércio exterior de manufaturados no Brasil. Nesse trabalho Tyler utilizou índices de necessidades de trabalho qualificado por unidade de produto utilizados por Donald Keesing para os Estados Unidos. 
Apesar de confirmar algumas hipóteses sobre o capital humano, encontrou o resultado paradoxal de que as exportações de manufaturados do Brasil eram naquela época mais intensivas em qualidade de trabalho do que as exportações dos países industrializados.

Considerando também a versão da teoria de Heckscher-Ohlin, que leva em conta o capital humano, Rocca e Mendonça (1972), utilizando dados coletados junto às indústrias brasileiras, com base na Lei dos dois terços, elaboraram novos indicadores de utilização de trabalho qualificado na indústria brasileira. Com base nessas informações os autores concluem que não parece existir evidência de que as exportações brasileiras sejam mais intensivas em trabalho qualificado relativamente às exportações dos países desenvolvidos. Pelo contrário, as exportações de manufaturados brasileiros eram relativamente intensivas em trabalho não qualificado, e as importações relativamente intensivas em trabalho qualificado. Os resultados dos autores parecem dar suporte à teoria de $\mathrm{H}-\mathrm{O}$, que considera $\mathrm{o}$ capital humano.

Carvalho e Haddad (1980) também procuraram testar a teoria de Heckscher-Ohlin para o Brasil. Os autores calculam requisitos diretos e indiretos de trabalho por Cr\$ 1 milhão de exportações e importações, utilizando as matrizes de insumo-produto de 1959, 1970 e 1971 disponíveis naquela época para o setor industrial brasileiro. Para cada um desses anos, os autores calcularam requisitos diretos e indiretos de trabalho em relação ao valor adicionado e em relação ao valor da produção. Os resultados obtidos parecem não conclusivos, pois para os anos de 1959 e 1970 os autores obtiveram que as importações de produtos manufaturados utilizavam mais trabalho por unidade de valor adicionado (ou de valor de produção) que as exportações. Ao passo que para 1971 os resultados foram opostos, ou seja, as exportações se mostraram mais absorvedoras de trabalho do que as importações. Tendo em vista esses resultados pouco conclusivos, os autores refizeram os cálculos levando em conta agora as inter-relações com o setor agrícola. Os resultados obtidos pelos autores para os anos de 1959 e 1970, considerando o setor agrícola, inverteram-se, mostrando que de fato as exportações de manufaturados eram cerca de duas vezes mais intensivas em trabalho que os substitutos das importações. Em outro trabalho Carvalho e Haddad (1977), utilizando a teoria do capital humano, constroem índices de qualificação do trabalho para o setor industrial, e mostram que para 
1959 o conteúdo médio de trabalho qualificado nas exportações de manufaturados era menor que no setor de importáveis; para 1971 as conclusões pareciam ambíguas.

Apesar dos trabalhos citados anteriormente tenham por objetivo testar a teoria de Heckscher-Ohlin para o Brasil, os testes realizados apresentam algumas dificuldades, explicadas em parte pela qualidade dos dados disponíveis na época em que os trabalhos foram realizados. Hidalgo (1985) realiza um novo teste empírico da teoria $\mathrm{H}-\mathrm{O}$, utilizando dados mais completos obtidos da matriz de insumo-produto disponíveis para o Brasil para 1970. O autor considera capital e trabalho como sendo os fatores de produção. Após realizar diversos ajustes, Hidalgo (1985) conclui que, considerando todas as formas possíveis de capital (incluindo a terra), os resultados mostram que os bens substitutos de importáveis eram significativamente mais intensivos em capital que os bens exportáveis. Por outro lado, considerando o conceito de capital mais restrito (excluindo o capital fundiário), essas conclusões se veem reforçadas, ou seja, as exportações são mais intensivas em trabalho quando comparadas com as importações, corroborando a teoria $\mathrm{H}-\mathrm{O}$ para o Brasil. Posteriormente Clements (1987) e Clements e Kim (1988), realizaram amplo estudo sobre comércio e distribuição da renda no Brasil, concluindo que apesar das barreiras tarifárias e não tarifárias no Brasil, os resultados obtidos eram consistentes com as previsões da teoria de H-O. Em outro trabalho realizado no começo dos anos 90 , e utilizando a abordagem tradicional, Sales (1993) não encontrou resultados empíricos que confirmem o teorema básico de $\mathrm{H}-\mathrm{O}$ no caso brasileiro. Segundo a autora, a evidência disponível não permite concluir que o Brasil tenha vantagem comparativa em produtos intensivos em mão de obra e desvantagem comparativa em produtos intensivos em capital.

Após o início do processo de abertura comercial e integração econômica, diversos trabalhos foram realizados na expectativa de um ambiente de comércio mais livre que revelasse as vantagens comparativas de cada país. Assim Vasconcelos (2001), utilizando o modelo Heckscher-Ohlin-Vanek (H-O-V), analisou as intensidades fatoriais do comércio brasileiro tanto em relação ao MERCOSUL, quanto em relação ao resto do mundo. A fim de realizar comparações o autor examina o período antes e após a integração. Vasconcelos conclui que para os anos de 1990 e 1996 o fluxo de comércio com o resto do mundo se revela não paradoxal, ou seja, os resultados indicam 
a validade da hipótese de o país ser abundante em trabalho relativamente ao capital. Logo o fluxo comercial exterior parece processar-se dentro dos princípios das vantagens comparativas estáticas. Quanto ao MERCOSUL, o autor analisou os anos 1982, 1990 e 1996, encontrando que para os três anos as exportações brasileiras se revelam mais intensivas em capital do que as importações, desta forma consoante com o esperado pela teoria tradicional do comércio de $\mathrm{H}-\mathrm{O}$, desde que se admita que o Brasil seja mais bem dotado de capital em relação aos outros países membros do bloco.

Boa parte dos testes empíricos da teoria de $\mathrm{H}-\mathrm{O}$ realizados recentemente utiliza a abordagem do capital humano. Dentro desse grupo, cabe destacar o trabalho de Machado (1997), que avalia o padrão de comércio externo brasileiro para o ano de 1980 do ponto de vista da qualificação da mão de obra empregada na produção de bens exportáveis e importáveis. Machado constrói um índice de qualificação da mão de obra muito elaborado, não tendo como base o salário, mas construído utilizando dados censitários e inquéritos especiais do IBGE, referentes à formação do trabalhador. Os resultados do teste mostraram que o Brasil exporta bens intensivos em mão de obra de baixa qualificação e importa bens intensivos em mão de obra qualificada, portanto, condizentes com a teoria. Outro trabalho que analisa o processo de liberalização comercial a fim de saber se o mesmo afetou ou não a alocação de recursos na economia brasileira é Soares (2002). O autor também utiliza a abordagem da qualificação da mão de obra a fim de avaliar se a liberalização comercial deslocou ou não recursos para os setores onde a economia brasileira possui maior dotação de fatores de produção. Os resultados obtidos por Soares (2002) mostram que a liberalização comercial conduziu a um aumento de participação, em termos de valor de produção e valor adicionado, de alguns setores produtivos associados às vantagens comparativas nacionais.

A teoria de Heckscher-Ohlin também tem sido objeto de análise no âmbito do comércio bilateral. Assim, por exemplo, Cardoso, Soares, Moreira e Loureiro (2005) analisaram as exportações do Brasil para a Alemanha em 2001 com base na intensidade da utilização do fator correspondente à qualificação da mão de obra. Os autores construíram um índice de qualificação de mão de obra utilizando os dados da Pesquisa Nacional por Amostra de Domicílios (PNAD) do IBGE. Com base nesse índice os autores encontraram que 75,3\% 
das exportações brasileiras para a Alemanha eram provenientes de produtos com alta intensidade de utilização de mão de obra não qualificada, sendo este o fator considerado abundante no Brasil. Embora os autores não analisem a intensidade de utilização de mão de obra qualificada das importações, concluem estarem os resultados em consonância com a teoria das vantagens comparativas.

Finalmente cabe mencionar o trabalho de Hernández Muriel (2005), que realiza uma análise econométrica das fontes das vantagens comparativas reveladas pelo comércio no Brasil para os períodos antes e após a liberalização comercial. A autora não calcula o uso dos fatores de produção no comércio, mas estima regressões das exportações líquidas utilizando dados em painel, como função dos requisitos diretos e indiretos, considerando quatro fatores de produção: trabalho não qualificado, trabalho qualificado, capital e terra. A análise empírica desenvolvida é apoiada no modelo teórico de H-O-V.

Os resultados obtidos pela autora com base em dados ajustados pelas mudanças tecnológicas mostram que tanto para o período anterior à liberalização comercial, quanto após a liberalização o Brasil revela vantagens comparativas no uso de trabalho não qualificado, do estoque de capital físico e da terra, e apresenta situação desfavorável na utilização de trabalho qualificado.

A revisão da literatura acima apresentada mostra algumas dificuldades encontradas pelos autores na tentativa de obter evidências empíricas da teoria de $\mathrm{H}-\mathrm{O}$ para o Brasil, principalmente quando o teste é feito com base na teoria tradicional, que considera capital e trabalho como sendo os dois fatores de produção. Os testes se apresentam mais bem sucedidos quando consideram o trabalho qualificado e o trabalho não qualificado como sendo os dois fatores de produção da economia. Outra limitação dos testes refere-se ao fato de que geralmente admitem a priori ser o Brasil relativamente mais bem dotado de trabalho não qualificado em relação ao resto do mundo; esta hipótese precisa ser verificada com base nos dados disponíveis. Por outro lado, conforme foi dito anteriormente, a estrutura do comércio exterior brasileiro apresenta mudanças importantes nas últimas décadas, em que os bens intensivos em recursos naturais e terra ocupam um espaço cada vez mais importante na pauta de exportações brasileiras. Os testes realizados para o Brasil não levam em conta o papel desse terceiro fator de produção no comércio. Dessa forma, neste trabalho,

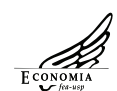


realizar-se-á um esforço na tentativa de superar algumas dessas limitações, admitindo a existência de três fatores de produção: capital, trabalho e recursos naturais (terra), além de verificar a abundância relativa de fatores entre o Brasil e os principais parceiros comerciais.

\section{Metodologia Utilizada para o Cálculo do Uso dos Fatores de Produção no Comércio Exterior Brasileiro}

O modelo padrão de comércio internacional baseado nas proporções dos fatores admite a existência de apenas dois produtos e dois fatores de produção. Para o objetivo deste trabalho, entretanto, admitir-se-á a existência de três fatores de produção e três tipos de produtos do ponto de vista da intensidade de fatores: produtos intensivos em recursos naturais, produtos intensivos em trabalho e produtos intensivos em capital. O primeiro grupo de produtos intensivos em recursos naturais se justifica, pois são indústrias que foram criadas para processar os recursos naturais e que são relativamente abundantes no Brasil. O segundo grupo de produtos são aqueles cujas indústrias são intensivas em trabalho, fator este que tradicionalmente tem sido considerado abundante na economia brasileira relativamente a países desenvolvidos. Finalmente, o terceiro grupo de produtos reflete o processo e industrialização no Brasil, baseado no fator capital, e que pode ser considerado fator relativamente escasso no Brasil. ${ }^{5}$

Existem duas maneiras para se mensurar as intensidades fatoriais: primeiro, poder-se-ia mensurar o volume físico dos insumos capital, trabalho e recursos naturais necessários para produzir um dado conjunto de bens; uma segunda forma de mensuração dos fatores consiste na estimativa da contribuição dos fatores de produção na formação do produto em cada setor da economia. Conceitualmente, a primeira dessas medidas é a mais recomendável para mensurar

5 Apesar de ser relevante a inclusão na análise de um terceiro fator de produção, recursos naturais, envolve alguns problemas tanto de natureza teórica quanto empírica. Existe a possibilidade que recursos naturais e capital, por exemplo, possam ser complementares e atuem juntos como substitutos brutos em relação ao trabalho. Por outro lado as informações disponíveis sobre renda da terra são muito parciais. Vanek (1963) analisa as dificuldades existentes quando se leva em conta a existência de um terceiro fator recursos naturais na teoria do comércio internacional. 
intensidades fatoriais. Somente em condições de concorrência e mobilidade perfeitas de fatores, as duas medidas levariam a obter o mesmo conteúdo de fatores e, portanto, seriam igualmente válidas. A utilização da primeira medida exigiria construir séries de estoque de fatores. Entretanto, os dados disponíveis sobre investimento não se apresentam no nível de detalhe requerido, de tal forma que permitam uma base para fazer a mensuração do estoque de capital. Assim, não se contando com essa informação, neste trabalho optou-se pela medida das participações dos fatores na renda gerada em cada setor. ${ }^{6}$

É possível estimar as remunerações recebidas pelos fatores trabalho e capital, tomando-se como base informações contidas na matriz de insumo-produto disponível para a economia brasileira. A renda gerada em cada setor da matriz está discriminada entre salários, encargos sociais, excedente operacional e outras remunerações. Com base na informação sobre remuneração do fator trabalho e valor adicionado em cada setor, pode-se obter como resíduo a remuneração do fator capital como indicado a seguir:

$$
\sum_{i=1}^{n} R_{i} K_{i}=\sum_{i=1}^{n} V A_{i}-\sum_{i=1}^{n} W_{i} L_{i}
$$

Onde VAi representa o valor adicionado a preços básicos e em termos brutos. As remunerações do trabalho são expressas pelo termo $W i L i$, que representa a folha de salários, encargos sociais e renda de autônomos. O resultado da subtração é o excedente bruto gerado em cada setor $i, R_{i} K_{i}$. Esta variável será utilizada como proxy da remuneração dos serviços de capital físico. Para a composição dos recursos naturais dos produtos, foi considerado como indicador o "coeficiente direto de recursos naturais". O coeficiente de requisitos diretos dos recursos naturais é obtido com base em dados da matriz insumo-produto, calculando para cada setor de atividade a participação dos produtos dos grupos: agropecuária, extrativa de minerais metálicos e combustíveis minerais. Essa variável é utilizada como proxy do uso direto de recursos naturais.

\footnotetext{
6 Segue, neste trabalho, a metodologia utilizada por Feistel e Hidalgo (2009), e Hidalgo (1985), para o cálculo das intensidades de fatores no comércio exterior, com base na renda gerada em cada setor.
} 
Após obter a remuneração dos fatores capital e trabalho, e a demanda dos insumos dos recursos naturais em cada setor $i$, podemos então dividir esses vetores pelo valor da produção correspondente de cada setor $i$. Com esse procedimento chegamos aos vetores " $p$ ", " $s$ " e " $t$ " os quais representam respectivamente a parcela da renda do capital, salários e insumos dos recursos naturais por unidade de valor de produção em cada setor $i$ :

$$
\begin{aligned}
p & =\left(p_{1}, p_{2}, \ldots \ldots, p_{n}\right) \\
s & =\left(s_{1}, s_{2}, \ldots \ldots ., s_{n}\right) \\
t & =\left(t_{1}, t_{2}, \ldots \ldots \ldots, t_{n}\right)
\end{aligned}
$$

O cálculo dos requisitos diretos e indiretos é determinado por procedimentos habituais. Assim, denominando de " $B=\left[b_{j i}\right]$ " a matriz de uso do insumo produtivo " $j$ " (capital, trabalho e recursos naturais) por unidade de valor de produto " $i$ ", e " $A=\left[a_{i j}\right]$ " a matriz de coeficientes de insumo-produto, pode-se calcular: $L=B(I-A)^{-1}$. A matriz " $L$ " representa a utilização total, direta e indireta do fator " $j$ " por cada unidade de produto " $i$ ". Com esta matriz pode-se aproximar as intensidades fatoriais dos produtos objeto de estudo e sua comparação com as intensidades fatoriais da economia como um todo. Da matriz " $L$ " tem-se:

$$
\begin{aligned}
& P_{i}=p .(I-A)^{-1} \\
& S_{i}=s .(I-A)^{-1} \\
& T_{i}=t .(I-A)^{-1}
\end{aligned}
$$

Dividindo agora (5) entre (6), obter-se-á um vetor que expressa a relação renda dos serviços do capital-salários em cada setor da economia $i: \beta_{i}=P_{i} / S_{i .}$. Da mesma forma, dividindo (5) entre (7), tem-se: $\alpha_{i}=P_{i} / T_{i}$, que mostra a relação entre renda dos serviços de capital-recursos naturais no setor da economia $i$. Finalmente, dividindo (7) entre (6) tem-se: $\gamma_{i}=T_{i} / S_{i}$, que mostra a relação entre insumos de recursos naturais-salários no setor da economia $i$. 
A utilização desses quocientes para analisar as intensidades de fatores em cada setor exige, porém, resolver outro problema. As participações das remunerações dos fatores gerados em cada setor da economia podem ser utilizadas para tirar conclusões sobre intensidades fatoriais, além de fazer comparações entre setores, desde que seja feita a hipótese de que a taxa de remuneração dos serviços do capital e a taxa de salário seja a mesma em todos os setores da economia. Essa hipótese não é válida no caso brasileiro, especialmente no que se refere à remuneração do trabalho. ${ }^{7} \mathrm{~A}$ evidência mostra também que em regiões menos desenvolvidas o diferencial de salário rural-urbano é ainda maior. Assim, as estimativas apresentadas neste trabalho sofreram ajustes para levar em conta a existência de distorções no preço dos fatores e o diferencial intersetorial de salários na economia brasileira. ${ }^{8}$

Apesar de teoricamente possível a existência de três fatores de produção no modelo de comércio como foi dito acima, existe o problema relativo à maneira como classificar os produtos segundo sua intensidade fatorial relativa; a solução foi encontrada por Leamer (1987) ao desenvolver o método dos "triângulos de dotações", descrito a seguir. Para desenvolver este método foi utilizado um modelo de equilíbrio geral de " $n$ " bens e três fatores de produção terra e recursos naturais (r), trabalho (l) e capital (k).

O modelo de Leamer foi originalmente utilizado para representar graficamente as dotações relativas dos três fatores para os diferentes países. No entanto, a mesma análise pode ser utilizada a fim de representar as intensidades fatoriais por produto. Londero e Teitel (1992) e Londero (1994) adaptaram o método do "triângulo de dotações" de Leamer para mostrar a representação triangular das intensidades fatoriais dos produtos. No modelo de Leamer, o problema da análise gráfica em três dimensões é superado através da interseção do ortante não negativo no espaço dos fatores em três dimensões com um plano fundo, apropriadamente definido, formando um "triângulo de dotações". Nesse espaço, os raios que partem da origem têm a mesma intensidade fatorial, e podem ser representados

\footnotetext{
7 Bacha (1979) foi um dos primeiros autores a identificar a existência de um diferencial entre salários urbanos e rurais na economia brasileira. Sobre os diferenciais de salários industriais na economia brasileira, ver Arbache e De Negri (2004) e Arbache, Dickerson e Green (2004).

8 No processo de construção das medidas de intensidades de fatores para o Brasil foram feitos ajustes utilizando as estimativas dos diferenciais de salários interindustriais elaborado por Arbache, Dickerson e Green (2004), dados referentes ao ano de 1999.
} 
por pontos em um gráfico de duas dimensões, dando origem ao triângulo de dotações relativas. Os três eixos coordenados no espaço de fatores são representados pelos vértices do "triângulo de dotações". Cada vértice representa um fator de produção. $\mathrm{O}$ "triângulo de dotações" tem a propriedade que para toda reta que parte de qualquer um dos três vértices tem a mesma proporção dos outros dois fatores de produção. Dessa forma, todos os produtos com a mesma relação $\mathrm{k} / \mathrm{r}$, por exemplo, $(\mathrm{k} / \mathrm{r})_{0}$, estarão sobre a reta que une o vértice inferior esquerdo na Figura 1, com o ponto correspondente a $(\mathrm{k} / \mathrm{r})_{0}$. Isto permite representar as intensidades fatoriais nos lados do triângulo.

A localização e a classificação de um determinado produto, segundo a intensidade fatorial, ficam determinadas pela interseção de duas retas que partindo dos vértices, cruzam os lados do triângulo nos pontos correspondentes ao valor da intensidade fatorial desse produto. Assim, por exemplo, na Figura 1 a localização do produto com as intensidades fatoriais $(\mathrm{k} / \mathrm{r})_{0}$ e $(\mathrm{r} / \mathrm{l})_{0}$ é assinalada com um círculo. O triângulo construído para um dado país é desenhado de tal forma que o setor produtivo desse país como um todo fique representado no centro do triângulo $(\mathrm{k} / \mathrm{l}=\mathrm{r} / \mathrm{l}=\mathrm{k} / \mathrm{r}=1)$. Considerando como ponto de referência a economia como um todo, é possível definir seis regiões segundo as intensidades fatoriais dos produtos nesse país, como na Figura 1 abaixo. Nas evidências empíricas que serão apresentadas neste trabalho, um produto é classificado como intensivo em um determinado fator de produção quando o for em relação aos outros dois fatores, por exemplo, os produtos localizados nas regióes 1 e 2 são considerados como sendo intensivos em $r$, pois o são tanto em relação a k quanto em relação a 1 independentemente da relação $k / 1$. Cabe notar que na região 1 esses produtos são intensivos em capital em relação ao trabalho, e na região 2 são intensivos em trabalho em relação ao capital. 


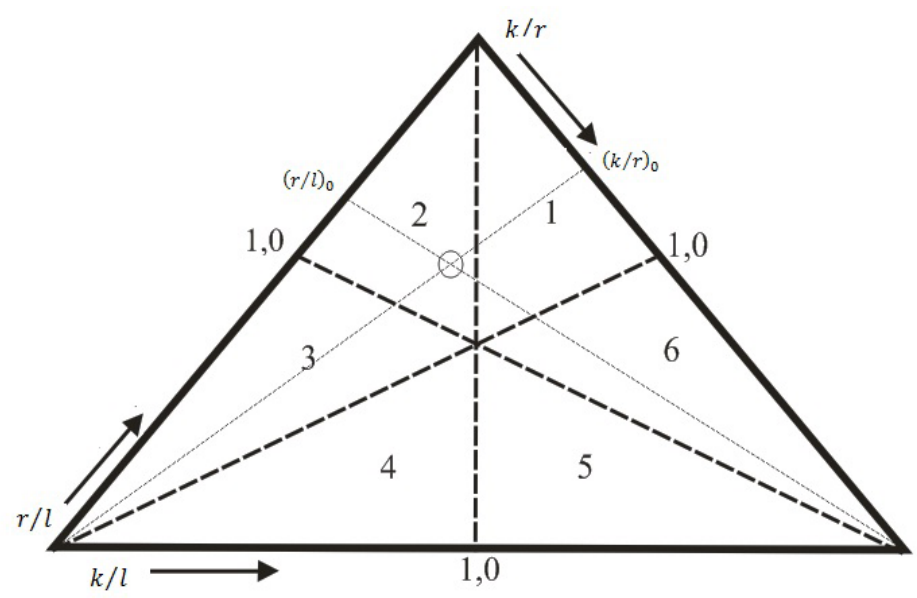

Figura 1 - Classificação das intensidades fatoriais

Dessa forma, seguindo esse critério de classificação dos produtos segundo as intensidades fatoriais, os produtos podem ser classificados da seguinte maneira: produtos localizados nas regiões 1 e $2(r / 1>1$ e $\mathrm{k} / \mathrm{r}<1$ ) são intensivos em recursos naturais, produtos localizados nas regiões 3 e $4(\mathrm{r} / 1<\mathrm{l}$ e $\mathrm{k} / \mathrm{l}<\mathrm{l})$ são intensivos em trabalho e, finalmente, produtos nas regiões 5 e $6(\mathrm{k} / 1>1$ e $\mathrm{k} / \mathrm{r}>1)$ são considerados intensivos em capital.

\section{As Dotações de Fatores de Produção na Economia Brasileira}

$\mathrm{Na}$ literatura sobre comércio exterior brasileiro geralmente partese da premissa de que o Brasil é relativamente mais bem dotado de recursos naturais do que de trabalho e capital, sendo este último fator visto como o mais escasso no país. Entretanto, esta hipótese precisa ser verificada com base nos dados disponíveis. A verificação empírica dessa questão é relativamente complexa, mas crucial, pois a adequação dos dados do comércio internacional brasileiro ao modelo de Heckscher-Ohlin depende dessa premissa. 
$\mathrm{Na}$ literatura existem duas definições já bem estabelecidas sobre abundância relativa de fatores para o caso padrão de dois bens e dois fatores de produção (capital e trabalho). A primeira definição baseiase nas dotações físicas dos fatores, ao passo que a segunda utiliza por base os preços relativos dos fatores de produção. De acordo com a definição física, o país 1 é abundante no fator trabalho (l) e o país 2 no fator capital $(\mathrm{k})$, quando $(\mathrm{k} / \mathrm{l})_{1}<(\mathrm{k} / \mathrm{l})_{2}$, sendo $\mathrm{k}$ e 1 as dotações de fatores em quantidades físicas e os sub índices os países. Por outro lado, segundo a definição baseada no preço relativo dos fatores, o país 1 é descrito como sendo relativamente abundante no fator 1 e o país 2 abundante no fator $\mathrm{k}$, quando $(\mathrm{Rk} / \mathrm{Rl})_{1}>(\mathrm{Rk} / \mathrm{Rl})_{2}$ antes do comércio, sendo Rk e Rl as remunerações dos fatores de produção k e 1, respectivamente. Entretanto, tendo em vista que os países já ingressaram no comércio internacional, então esta segunda definição com base no preço dos fatores não pode ser utilizada para verificar empiricamente as dotações relativas de fatores. Como se sabe, o livre comércio atua no sentido de igualar internacionalmente os preços dos fatores de produção, não refletindo seus preços a abundância relativa de fatores em cada país. Dessa forma a verificação empírica da dotação relativa de fatores deve ser feita com base na definição física.

Por outro lado, tendo em vista que neste trabalho estamos considerando a existência de três fatores de produção na economia, então a estimativa da dotação relativa de fatores para o Brasil será feita utilizando como base a metodologia do "triângulo de dotações" de Leamer (1987), descrita a seguir."

Quando existem três fatores de produção (r, 1 e k), as dotações de fatores do país j podem ser representadas no subespaço $(\mathrm{r}, \mathrm{l}, \mathrm{k})$ através do vetor $\left[\mathrm{v}_{\mathrm{j}}\right]=\left(\mathrm{r}_{\mathrm{j}}, 1_{\mathrm{j}}, \mathrm{k}_{\mathrm{j}}\right)$. Tendo em vista que as dotações de fatores de produção dos países são assumidas não negativas, a análise fica restrita ao ortante não negativo desse subespaço. A interseção do ortante não negativo no subespaço dos fatores em três dimensões, com um plano fundo resulta na formação de um triângulo chamado "triângulo de dotações". Os três eixos coordenados no espaço tridimensional de fatores são representados pelos vértices do "triângulo de dotações". Os vetores de dotações de fatores de produção dos países podem ser representados, no espaço de duas dimensões, por pontos dentro do triângulo formado, em que o vetor $\left[\mathrm{v}_{\mathrm{j}}\right]$ intercepta

9 Para maiores detalhes sobre a metodologia do "triângulo de dotações", ver Leamer (1987) e Londero (1994). 
o plano definido no ortante não negativo. O triângulo formado tem a propriedade de que cada ponto de dotação que se encontra na linha reta traçada com origem em qualquer um dos vértices tem a mesma proporção dos outros dois fatores de produção.

Da mesma forma cada uma das dotações relativas de fatores de produção do país $j$ pode ser representada no triângulo através de um ponto. A dotação relativa de fatores de produção de cada país estará associada a apenas um ponto dentro do triângulo, e esse ponto está determinado pela interseção de dois raios, que partindo dos vértices do triângulo interceptam o cateto oposto do triângulo, no ponto correspondente à respectiva proporção de fatores de produção desse país.

A fim de estimar as dotações relativas de fatores de produção na economia brasileira, consideraram-se os principais parceiros comerciais do Brasil que tivessem informações disponíveis. Ao todo foram considerados 32 países. As informações foram facilitadas com base em dados divulgados pela Organização para a Cooperação e Desenvolvimento Econômico (OCDE). As informações utilizadas para cada um dos países são referentes à formação bruta de capital fixo (capital), e população economicamente ativa ocupada (trabalho). As informações sobre recursos naturais (terra) foram aproximadas com base em dados sobre terras cultivadas em cada país. Os dados são referentes ao ano de 2005.

A metodologia de Leamer (1987) consiste em calcular inicialmente o ponto central do triângulo e que corresponde ao ponto médio das razões das dotações de recursos naturais, trabalho e capital dos países da amostra. As linhas da Figura 2, desenhadas a partir dos vértices, indicam que as razões médias das dotações de fatores de todos os 32 países considerados em 2005 são de aproximadamente US\$17.800,00 de capital por trabalhador, 1,47 hectares de terra arável por trabalhador, e US\$19.200,00 de capital por hectare de terra arável.

Depois de identificado o ponto central do "triângulo de dotações", ficam definidas seis regiões de dotações relativas, da mesma forma como foram definidas as intensidades fatoriais dos bens a partir das seis regiões da Figura 1. Assim, a localização no triângulo das razões das dotações de cada um dos países, que pode ser comparada com 
as razões das dotações médias dos países como um todo, determina sua intensidade fatorial. Os resultados que foram obtidos e mostrados na Figura 2 são os esperados. Os países industrializados (Japão, Alemanha, Estados Unidos, etc.), mostram uma alta relação capital por trabalhador. No caso particular do Brasil, temos que o país se destaca por ser relativamente bem dotado em recursos naturais (terra), localizando-se na área do triângulo o qual possui mais terra arável por trabalhador que a média dos outros países. Por outro lado, o país apresenta menos capital por trabalhador e menos capital por terra arável que a média dos outros países da amostra, ver Figura 2.

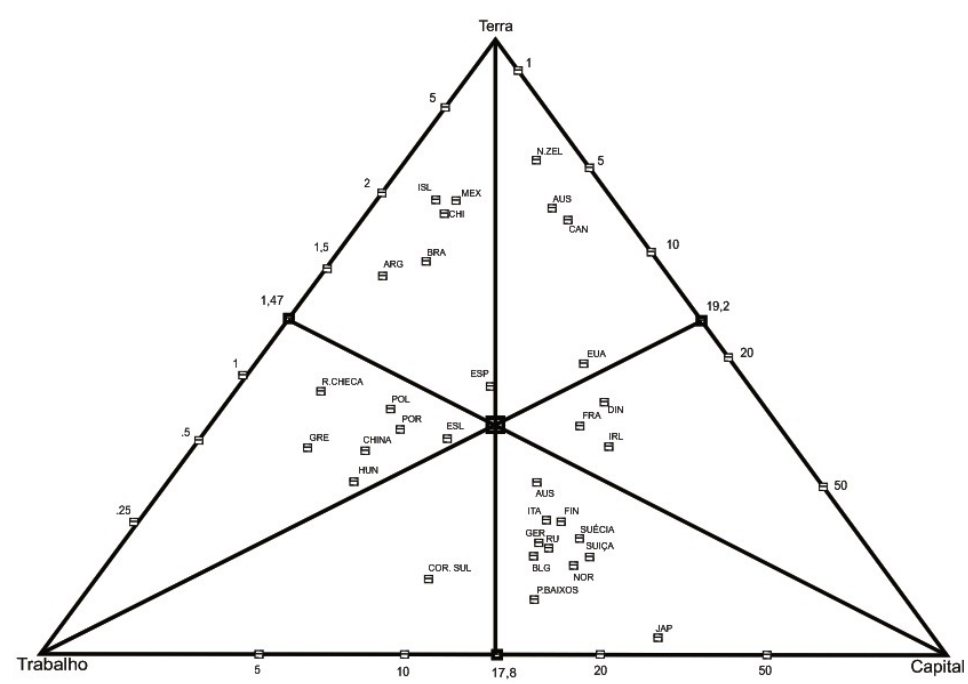

Figura 2 - Triângulo de dotações de fatores para diversos países, 2005

Fonte: Construído pelos autores com base em dados da Organização para a Cooperação e Desenvolvimento Econômico (OCDE), 2005.

\section{Resultados Obtidos}

O conjunto de dados utilizados a fim de calcular o uso dos fatores de produção nos diferentes setores produtivos da economia brasileira foi obtido da Matriz de Insumo-Produto de 2005 elaborada pelo Instituto Brasileiro de Geografia e Estatística (IBGE). Os dados sobre fluxos de comércio do Brasil, segundo produtos e países de destino e origem foram obtidos do Ministério do Desenvolvimento, Indústria e Comércio (MDIC) e disponíveis através do Sistema 
Alice. As informações sobre o comércio estão disponíveis segundo classificação da Nomenclatura Comum do MERCOSUL (NCM). Assim, foi necessário realizar a compatibilização dos dados sobre o comércio exterior no período proposto no trabalho, a fim de torná -los compatíveis com a respectiva classificação da Matriz de InsumoProduto do Brasil de 2005. Os dados objetos deste trabalho referemse ao período de 1989-2010. Assim inicialmente na subseção 5.1 classificam-se os produtos segundo sua intensidade fatorial relativa obtida e na subseção 5.2 realiza-se a análise correspondente.

\subsection{Classificação dos Setores Produtivos Segundo a Intensidade Fatorial}

Com base nos dados disponíveis da Matriz de Insumo-Produto do Brasil, e utilizando a metodologia desenvolvida por Leamer (1987) e adaptada por Londero e Teitel (1992), descrita na seção três desse trabalho, foi possível construir a Figura 3 e obter a classificação da estrutura fatorial das exportações e importações para o Brasil referente ao período em análise.

Conforme já foi dito, dizemos que um determinado produto é intensivo em um dos fatores de produção se, quando se lhe compara com o valor médio da economia como um todo, for intensivo em relação aos outros dois fatores de produção, independentemente da terceira relação. A classificação de um produto fica determinada pela interseção das retas que saindo dos vértices, cruzem os lados do triângulo nos pontos correspondentes ao valor da intensidade fatorial relativa desse produto.

Dessa forma, a classificação da estrutura das intensidades fatoriais que foi obtida, apresentada graficamente na Figura 3, mostra que os setores que se localizam nas regiões 1 e 2 apresentam coeficientes $\mathrm{k} / \mathrm{r}<1$ e $\mathrm{r} / \mathrm{l}>1$, e portanto são classificados como produtos intensivos em recursos naturais, segundo critério adotado neste artigo. Assim, para o Brasil no ano de 2005 foram classificados treze setores como sendo intensivos em recursos naturais: Agropecuária e Silvicultura, Pecuária e Pesca, Minério de Ferro, outros da Indústria Extrativa Mineral (Exceto Combustíveis), Alimentos e Bebidas, Produtos de Fumo, Celulose e Produtos de Papel, Petróleo e Gás,

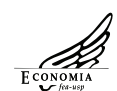


Álcool, Defensivos Agrícolas, Cimento, outros Produtos Minerais Não Metálicos, Fabricação de Aço e Derivados.

Na Figura 3, os setores que possuem os coeficientes $r / 1<1$ e $k / 1<1$, localizados nas regiões 3 e 4 , são classificados como setores intensivos em trabalho. Para o Brasil, em 2005, foram classificados apenas cinco setores como sendo intensivos em trabalho: Têxteis, Artigos de Vestuário e Acessórios, Artefatos de Couro e Calçados, Produtos de Madeira-Exclusive Móveis, Móveis e Produtos das Indústrias Diversas.

Finalmente os produtos intensivos em capital, bens que geralmente possuem maior valor agregado, têm o maior número de setores na classificação realizada, ao todo foram classificados vinte e seis setores. Nesta categoria, são classificados os produtos dos setores que possuem coeficientes $\mathrm{k} / \mathrm{l}>\mathrm{l}$ e $\mathrm{k} / \mathrm{r}>\mathrm{l}$ e pertencem às regiões 5 e 6 na classificação do Triângulo de Leamer. Os produtos que pertencem a esta categoria são os seguintes setores: Refino de Petróleo e Coque, Produtos Químicos, Fabricação de Resina e Elastômeros, Produtos Farmacêuticos, Perfumaria, Higiene e Limpeza, Tintas, Vernizes e Esmaltes, Produtos Químicos Diversos, Artigos de Borracha e Plástico, Metalurgia de Metais não Ferrosos, Produtos de Metal (Exclusive Máquinas), Jornais, Revistas e Discos, Máquinas e Equipamentos (Inclusive Eletrodomésticos), Máquinas para Escritório, Máquinas, Aparelhos e Matérias Elétricos, Material Eletrônico e Equipamento Comum, Aparelhos, Instrumentos Médicos Hospitalares, Automóveis, Camionetes e Utilitários, Caminhões e Ônibus, Peças e Acessórios para Veículos, Outros Equipamentos de Transporte. 


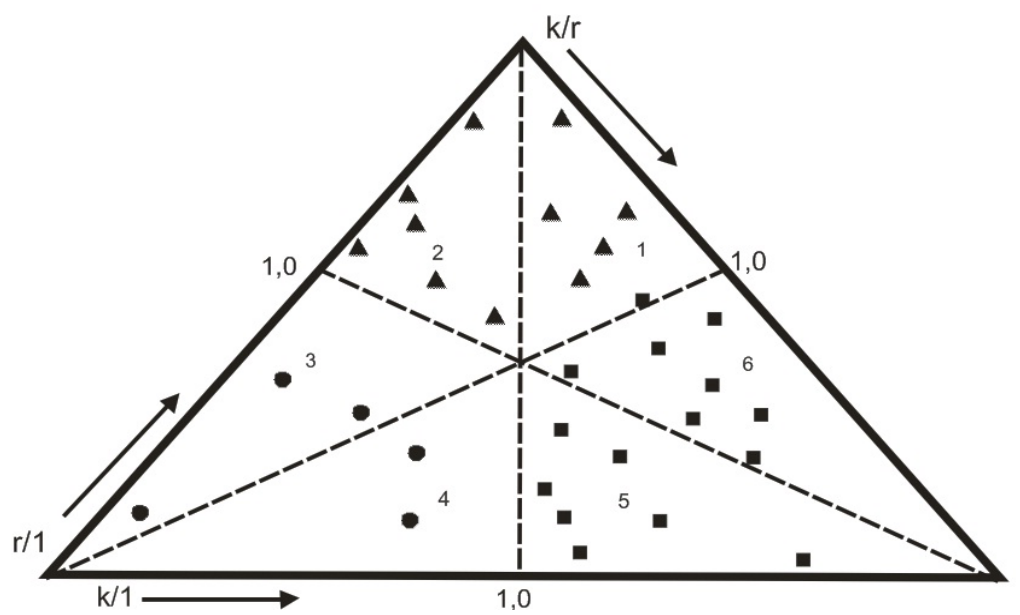

Figura 3 - Classificação das intensidades fatoriais

Fonte: Figura construída a partir de dados da Matriz de Insumo-Produto do Brasil de 2005.

Legenda: \ Setores Intensivos em Recursos Naturais, regióes 1 e 2 do triângulo;

- Setores Intensivos em Trabalho, regiões 3 e 4 do triângulo;

- Setores Intensivos em Capital, regiões 5 e 6 do triângulo.

\subsection{Intensidades Fatoriais no Comércio Exterior Brasileiro}

Os principais resultados obtidos para o Brasil nas relações comerciais com o resto do mundo estão apresentados nos Gráficos 1 e 2 a seguir, dados referentes ao período de 1989 a 2010. O Gráfico 1 mostra a participação das exportações brasileiras no comércio com o resto do mundo, segundo sua intensidade fatorial. Os resultados mostram que houve um predomínio de produtos intensivos em recursos naturais ao longo do período analisado, que tem como contrapartida em segundo plano a participação das exportações de produtos intensivos em capital e seguida em patamar inferior, as exportações brasileiras de bens intensivos em trabalho. Este resultado era esperado com base na teoria $\mathrm{H}-\mathrm{O}$, tendo em vista as dotações fatoriais relativas da economia mostradas anteriormente na seção 4 .

Apesar de ser clara a tendência de longo prazo de aumento de participação dos produtos intensivos em recursos naturais na pauta de exportações brasileira, é possível identificar dois momentos distintos ao longo do período analisado - ver Gráfico 1. O primeiro mostra 
um movimento convergente na participação relativa das exportações brasileiras, entre bens intensivos em capital e bens intensivos em recursos naturais. Esta tendência é refletida pelo aumento de 1989 ao ano de 2000, na participação relativa dos bens intensivos em capital e redução dos bens intensivos em recursos naturais. O segundo movimento ocorre a partir do ano de 2001 ao inverter a tendência de convergência, entre estas duas categorias de intensidades de fatores, quando os produtos intensivos em capital diminuem a sua participação relativa e os produtos intensivos em recursos naturais voltam a aumentar a participação no total exportado pelo Brasil para o resto do mundo. Observe-se que o aumento na participação dos produtos intensivos em recursos naturais durante o período de 2000 a 2010 é firme e sólido; durante este período a participação desses bens passou de $47,0 \%$ para $65,1 \%$, ou seja, um aumento de participação na pauta de exportações de $18,1 \%$.

Quanto aos bens intensivos em capital, em particular, os resultados mostram que no período de 1989 a 2000 houve um aumento significativo na participação relativa destes bens. É possível que o crescimento da produtividade industrial e a consolidação do MERCOSUL neste período ajudem a explicar o resultado. ${ }^{10} \mathrm{~A}$ análise da evolução do uso dos fatores de produção mostra que as exportações de produtos intensivos em capital representavam em 1989 cerca de 29\% das exportações brasileiras. Ressalta-se que apesar de o predomínio, ao longo do período analisado, das exportações de produtos intensivos em recursos naturais, houve um aumento continuo da importância dos produtos intensivos em capital até o ano 2000, que com uma participação de 42,1\% naquele ano atinge o máximo de sua representatividade nas exportações brasileiras em todo o período analisado. Porém, após o ano de 2000, os produtos intensivos em capital mostram uma queda continua na sua importância relativa, chegando ao ano de 2010 a níveis inferiores de 1989, com representatividade de 29,1\% em 2008 e 27,0\% em 2010, (ver Gráfico 1).

\footnotetext{
${ }^{10}$ Neste período houve significativo crescimento da produtividade industrial na economia brasileira, ver a respeito, por exemplo, Bonelli e Fonseca (1998) e Hidalgo (2002). Por outro lado conforme foi visto na seção 2 deste trabalho existem evidências empíricas que mostram as exportações brasileiras para o MERCOSUL, durante esse período, como sendo intensivas em capital - ver Vasconcelos (2001) e Yeats (1998). Este último autor argumenta que existem evidências de desvio de comércio no fluxo comercial intra-MERCOSUL. Feistel e Hidalgo (2009) e Feistel (2006) também mostram que o comércio Brasil-MERCOSUL é altamente intensivo em capital.
} 


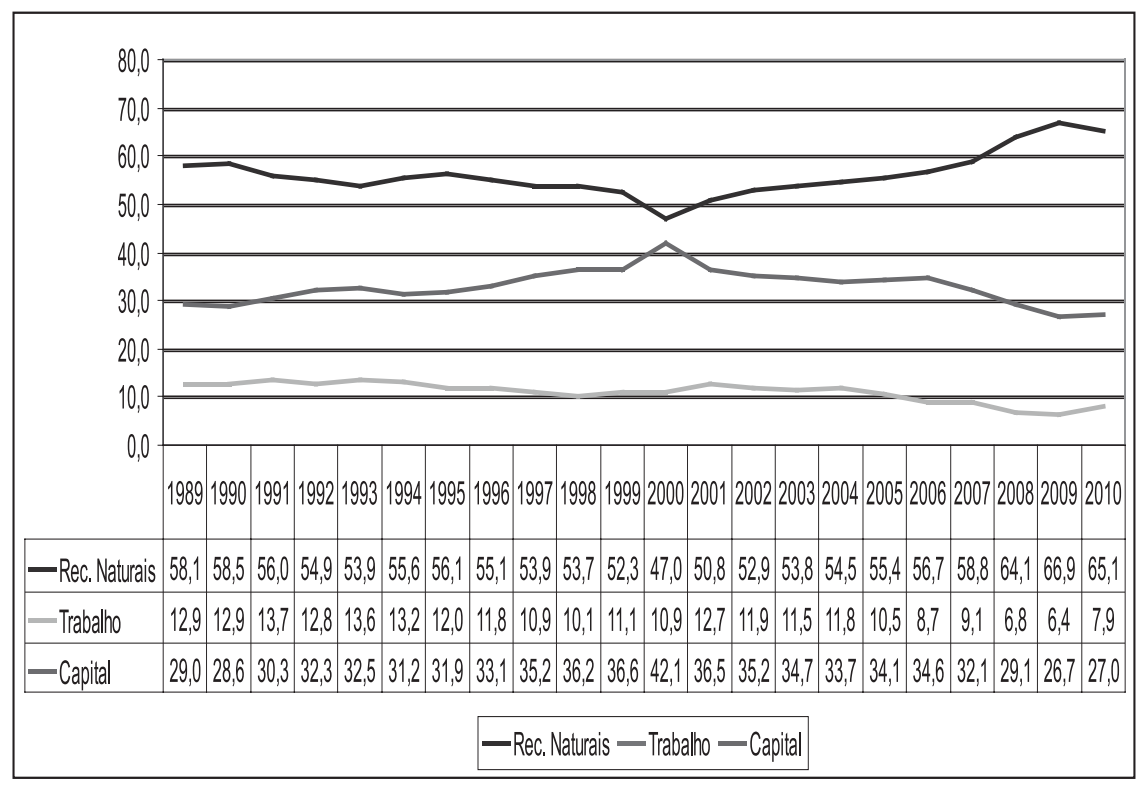

Gráfico 1 - Intensidades fatoriais das exportações brasileiras1989/2010, em \%

Fonte: Construído com base em dados da Matriz de Insumo Produto do Brasil, 2005, e dados do fluxo de comércio do Sistema Alice Web do MDIC.

Ainda no Gráfico 1, observa-se que para os produtos intensivos em recursos naturais, há como ponto de inflexão o ano de 2000, que com a representatividade de $47,0 \%$, começa a reverter a tendência de queda na participação relativa desses bens nas exportações brasileiras. Nota-se que em 1989, início do período analisado, as exportações brasileiras de bens intensivos em recursos naturais representavam $58,1 \%$ do total exportado. No entanto, com os adventos da abertura comercial brasileira, criação e expansão do comércio no MERCOSUL nos anos 90, fizeram com que a modernização da indústria brasileira, representada pelas exportações de bens intensivos em capital ocupasse maior espaço no comércio exterior brasileiro.

Este movimento fez com que as exportações de bens intensivos em recursos naturais tivessem reduzida sua participação relativa, atingindo o patamar de 47,0\% em 2000. Porém, o aumento da inserção chinesa no comércio internacional, a especialização no comércio internacional e a elevação dos preços das commodities, foram fatores que induziram o setor de bens intensivos em recursos naturais a 
reagir e aumentar sua representatividade nas exportações, chegando a representar $64,1 \%$ em 2008 e $65,1 \%$ em $2010,{ }^{11}$ do total exportado pela economia brasileira para o resto do mundo.

Com relação aos bens intensivos em trabalho, observa-se no Gráfico 1 que os mesmos mantiveram uma participação média nas exportações brasileiras da ordem de 11,0\%, no período de 1989 a 2010. Entretanto, houve no período analisado uma clara redução na participação relativa desses bens. Com efeito, no ano de 1989 a participação dos bens intensivos em trabalho era de $12,9 \%$, passando para 10,9 \% em 2000 e 7,9\% em 2010. A importância relativa dos setores de bens intensivos em trabalho é representada pelos produtos dos setores Têxteis e Artefatos de Couro e Calçados, que juntamente representam em média mais de $60,0 \%$ do total exportado pelo Brasil em bens intensivos em trabalho no período analisado. O setor de Artefatos de Couro e Calçados, apesar de sofrerem com a concorrência dos produtos da China, tem mantido uma participação relativa média de mais de $45,0 \%$, tendo alcançado em 1989 a cifra de 47,0\% do total exportado em bens intensivos em trabalho, e nos anos de 2000 e 2008, apesar de um pequeno decréscimo, sua participação permaneceu significativa de $45,0 \%$ e $43,0 \%$, respectivamente. Já o setor têxtil apresenta uma menor representatividade no período, atingindo $27,0 \%$ em 1989, 13,0\% no ano de 2000, e recuperando-se para cerca de $20,0 \%$ em 2008. A liberalização comercial no setor provocado pelo fim do Acordo das Multifibras em 1994 e a transferência gradual de produtos restritos por quotas para o Acordo sobre Têxteis e Vestuários, provocaram impactos sobre o comércio mundial do setor, deslocando a produção para países com baixos custos de produção como é o caso da China, Índia, e outros países. Esses países com abundante mão de obra tem aproveitado a liberalização no setor para aumentar as exportações, aproveitando as vantagens comparativas em bens intensivos em trabalho.

Os resultados obtidos das intensidades fatoriais dos bens importados pelo Brasil estão apresentados no Gráfico 2 a seguir. Os dados do Gráfico 2 mostram a participação dos produtos importados pelo Brasil do resto do mundo segundo sua intensidade fatorial relativa, período de 1989 a 2010. Como esperado pela teoria, os resultados

${ }^{11}$ Ressalta-se que cerca de $80 \%$ das exportações brasileiras para a China consistem de soja e minério de ferro, bens intensivos em recursos naturais. Por outro lado o Comércio Internacional de 2009 foi afetado pela crise Financeira Internacional de 2008, reforçando a tendência pelo Brasil na exportação de bens primários. 
mostram um predomínio de produtos importados intensivos em capital ao longo do período estudado. Os resultados parecem coerentes com a teoria das vantagens comparativas na versão de HeckscherOhlin, levando em conta que o fator capital é relativamente escasso no Brasil conforme foi visto anteriormente. As evidências têm como contrapartida a participação das importações de produtos intensivos em recursos naturais, e seguido em patamar bem inferior às importações dos bens intensivos em trabalho. Esta situação, porém, não foi definitiva ao longo do período, pois em 1989 os bens intensivos em recursos naturais representavam 52,2\% das importações brasileiras, superando inclusive as importações de bens intensivos em capital, que representava $43,5 \%$ naquele ano. No que se refere à participação dos bens intensivos em trabalho nas importações brasileiras, ela é relativamente pequena, média de $4,7 \%$ ao longo do período analisado, porém ela é estável como visualizado no Gráfico 2.

O comportamento das intensidades fatoriais nas importações brasileiras nas últimas duas décadas certamente está relacionado com o processo de liberalização comercial. No início dos anos 90, com a abertura comercial, redução das tarifas e a necessidade de modernização da indústria brasileira, a fim de torná-la mais eficiente e competitiva, são elementos que afetaram significativamente o panorama das importações brasileiras nesse período. Dessa forma, no ano de 1993 a participação das importações de bens intensivos em capital, 49,3\%, já superava a participação das importações de bens intensivos em recursos naturais que se situava em $44,2 \%$.

As importações embaladas pelo aprofundamento da abertura comercial, a tendência de aumento de representatividade das importações brasileiras de bens intensivos em capital e recuo representativo dos bens intensivos em recursos naturais, segue em ritmo acelerado ao longo dos anos 90. Isto é percebido quando em 1999 as importações de bens intensivos em recursos naturais representavam apenas 31,5\% do total importado pela economia brasileira e, neste mesmo ano, a representatividade das importações de bens intensivos em capital atingiu 63,9\%. A exceção é feita aos bens intensivos em trabalho que mantiveram sua média em torno de 5,9\% de 1993 a 1999 (ver Gráfico 2). 


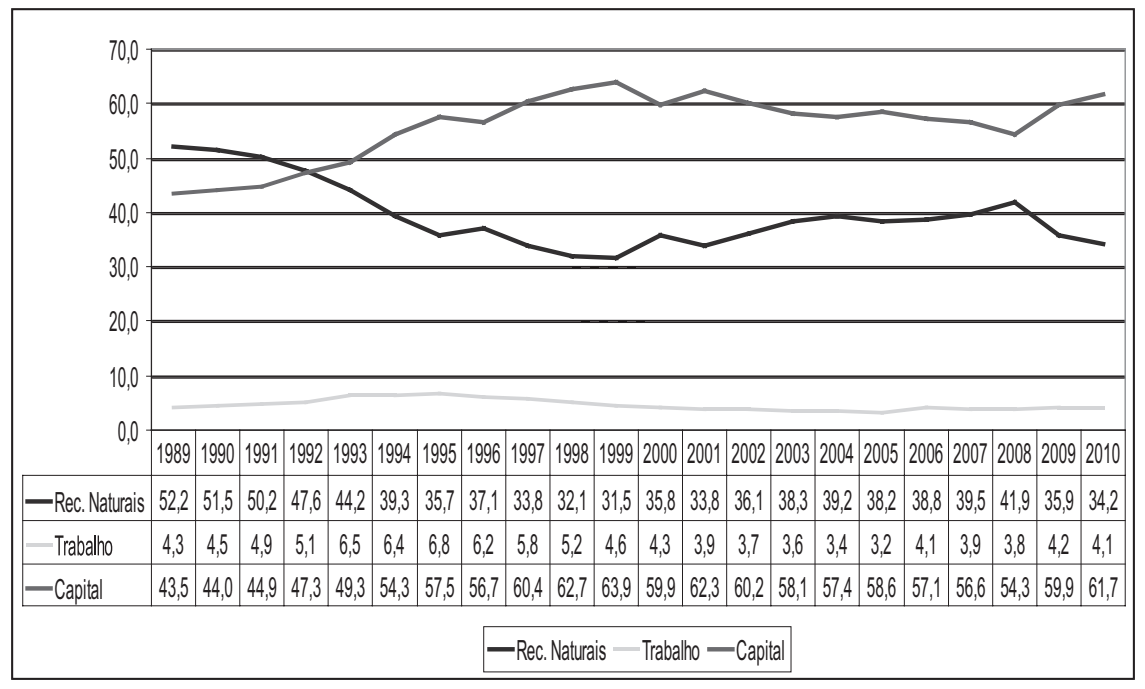

Gráfico 2 - Intensidades fatoriais das importações brasileiras 1989/2010, em \% Fonte: Construído com base em dados da Matriz de Insumo Produto do Brasil, 2005, e dados do fluxo de comércio do Sistema Alice Web do MDIC.

Embora a tendência de longo prazo de aumento de participação dos produtos intensivos em capital na pauta de importações brasileira seja clara, é possível identificar momentos distintos ao longo do período analisado. Assim, coincidindo com o advento da crise na economia brasileira ocorrida em 1999 e da crise na economia Argentina em 2002, com impactos sobre o comércio no MERCOSUL, podemos identificar um momento diferente das importações de bens intensivos em capital versus recursos naturais.

Com efeito, observa-se que no ano de 2000 inicia-se um lento processo de reversão da tendência verificada nos anos 90; assim, até 2008 ocorreram pequenos e contínuos aumentos na participação relativa das importações de bens intensivos em recursos naturais, que no período teve a representatividade média de 37,9\%. Inversamente, houve pequena redução das importações de bens intensivos em capital, que tiveram participação média de $58,2 \%$ no período de 2000 a 2008. No entanto, nos últimos anos da série, devido à aceleração do comércio mundial, ascensão das economias asiáticas e da elevação dos preços internacionais das commodities, esta tendência não se confirma e os bens intensivos em capital voltaram a aumentar 
sua representatividade com 59,9\% em 2009 e 61,7\% em 2010; em contrapartida as importações intensivas em recursos naturais representaram neste período $35,9 \%$ e $34,2 \%$, respectivamente. Por fim, temos que os bens intensivos em trabalho mantiveram uma média representativa de $3,8 \%$ ao ano durante o período de 2000 até 2010 , participação esta levemente inferior à média de $5,6 \%$ verificada na década anterior. Esse resultado era o esperado com base na teoria de Heckscher-Ohlin, pois como ficou evidenciado na Figura 2 acima, o Brasil é relativamente bem dotado de recursos naturais em relação tanto ao trabalho quanto em relação ao capital, mas relativamente escasso de capital em relação ao trabalho.

\section{Conclusões}

Neste artigo foram analisadas as mudanças acontecidas na estrutura do comércio exterior brasileiro em termos de uso dos recursos produtivos no comércio durante o período após a abertura comercial. Os dados sobre comércio mostram que durante esse período os grupos de produtos primários tiveram altas taxas de crescimento nas exportações, fazendo com que a participação dos mesmos passasse a representar mais de $50 \%$ do total exportado pelo país no ano de 2010. Os produtos manufaturados, por sua vez, tiveram uma queda significativa na participação relativa nas exportações ao longo do período analisado.

Diferente das exportações, no período, as importações brasileiras apresentam uma redução significativa na participação relativa dos grupos de produtos primários, e um correspondente incremento na participação relativa dos manufaturados, principalmente daqueles mais intensivos em capital. Com base na teoria do comércio das proporções de fatores de Heckscher-Ohlin, na versão de um modelo de três fatores de produção, e utilizando a técnica de insumo-produto, foi feita uma análise mais aprofundada a fim de mensurar o conteúdo dos fatores de produção no comércio exterior brasileiro.

Os resultados obtidos mostram uma tendência de longo prazo de aumento de participação dos produtos intensivos em recursos naturais e queda de participação dos produtos intensivos em capital e trabalho na pauta de exportações brasileiras. Por outro lado, no que 
se refere às importações, estas mostram uma inequívoca tendência de crescente participação dos produtos intensivos em capital e uma queda de participação de produtos intensivos em recursos naturais. Dessa forma, os resultados obtidos parecem mostrar uma tendência de especialização do comércio exterior brasileiro segundo o princípio das vantagens comparativas estáticas após a abertura comercial, pois a economia brasileira é reconhecidamente bem dotada de recursos naturais (terra e minerais abundantes), e menos dotada de capital (tanto físico, quanto humano), em relação aos principais parceiros comerciais.

Assim, a mudança na estrutura do comércio exterior brasileiro não é recente. Vem acontecendo desde há alguns anos e parece obedecer a um processo natural de aproveitamento de vantagens naturais do país diante de um comércio internacional cada vez mais livre. O fenômeno de mudança na composição parece ser de longo prazo e fruto de aproveitamento de vantagens comparativas no comércio internacional.

Os desafios para o futuro do comércio exterior brasileiro parecem estar relacionados com a formulação de uma política científica, tecnológica e comercial, que permita a qualificação e a incorporação de maior valor agregado nos produtos em que o país tem vantagens comparativas. Entretanto, o sucesso no comércio internacional com base nas vantagens comparativas dependerá também do andamento das negociações no âmbito da Organização Mundial do Comércio.

A eliminação tanto dos subsídios à produção de bens primários quanto das restrições comercias, incluindo as tarifas moduladas nos países industrializados, são fundamentais para o sucesso da estratégia com base nas vantagens comparativas.

Como todo trabalho de natureza empírica, este também tem suas limitações. A principal delas refere-se aos dados que foram utilizados. Idealmente o cálculo das intensidades fatoriais deveria ser realizado com base no volume físico dos insumos capital, trabalho e recursos naturais necessários para produzir os bens. Não se contando com essa informação, foi preciso utilizar a medida das participações dos fatores na renda gerada em cada setor; este procedimento, entretanto, depende de algumas hipóteses que foram feitas. Outra limitação refere-se ao fato da utilização de apenas uma matriz de insumo-pro- 
duto de 2005. O período analisado é muito longo e certamente houve mudanças tecnológicas importantes no período e que não foram consideradas. Melhorias nos resultados certamente poderiam ser obtidas levando em conta esses elementos.

\section{Referências}

ARBACHE, J. S. E J. A. DE NEGRI 2004, Filiação Industrial e Diferencial de Salários no Brasil, Revista Brasileira de Economia 58 (2), pág. 159-184.

ARBACHE, J. S., A. Dickerson E F. Green 2004, Assessing the Stability of the Inter- Industry Wage Structure in the Face of Radical Economic Reforms, Economics Letters, 83, 149-155.

BACHA, E. 1979, Crescimento econômico, salários urbanos e rurais: o caso do Brasil, Pesquisa e Planejamento Econômico, 9 (3): 585-628.

BONELLI, R. e FONSECA, R. 1998, Ganhos de Produtividade e de Eficiência: Novos Resultados para a Economia Brasileira. Texto para Discussão N.557, IPEA, RJ.

CARDOSO, A. S., F. A. SOARES, T. B. S. MOREIRA E P. LOUREIRO, 2005, Vantagens Comparativas e Restrições Comerciais- Uma Avaliação do Comércio Brasil/Alemanha em 2001, Revista de Economia Contemporânea, Vol. 9 no. 3 pág. 583 a 614.

CARVALHO, J. L. E C. L. HADDAD 1977, Um índice de qualidade de mão-de-obra: uma aplicação do conceito de capital humano. Revista Brasileira de Economia 31 (1): 31-43.

CARVALHO, J. L. E C. L. HADDAD 1980, Estratégias comerciais e absorção de mão-de-obra no Brasil. (Série Pesquisas EPGE, n. 1) Fundação Getúlio Vargas, Rio de Janeiro.

CLEMENTS, BENEDICT J. e KWAN S. KIM 1988, Comércio Exterior e Distribuição da Renda: O Caso Brasileiro, Pesquisa e Planejamento Econômico, abril 1988, Vol. 18 (1), pág. 17-36.

CLEMENTS, BENEDICT J. 1987, The Heckscher-Ohlin Theorem of International Trade: New Empirical Tests for Brazil, Journal of Applied Business Research, 3: 16-24, Winter 1987.

ETHIER, W. 1984, Higher Dimensional Issues in Trade Theory. Handbook of International Economics, vol. I , pp. 131-184, eds. R. W. Jones e P. B. Kenen, Elsevier Science Publishers, North Holland.

FEISTEL, P. R. 2006, A Natureza do Comércio das Regiões Brasileiras no MERCOSUL. Tese de Doutorado, Departamento de Economia, UFPE, Recife, Brasil.

FEISTEL, P. R. E A. B. HIDALGO 2009, O Comércio das Regiões Brasileiras Nordeste Sudeste e Sul no MERCOSUL : Uma Abordagem das Vantagens Comparativas, Anais do XXXVII Encontro Nacional de Economia da ANPEC, realizado em Foz do Iguaçu, Paraná, dez. de 2009.

HERNÁNDEZ MURIEL, BEATRIZ CRISTINA. 2005. Três ensaios sobre as predições de Heckscher-Ohlin: questões teóricas e testes empíricos, Tese de Doutorado em Economia defendida na PUC/ RJ, Cap. 2, Tese ganhadora do Prêmio Halarambus Simeonidis da ANPEC 2005 (Natal/RN).

HIDALGO, A. B., 2002, O Processo de Abertura Comercial Brasileira e o Crescimento da Produtividade, Revista Economia Aplicada, Vol. 6, No. 1, p. 79 a 95.

, 1985, Intensidades Fatoriais na economia brasileira: novo teste empírico do Teorema de Heckscher-Ohlin, Revista Brasileira de Economia, vol. 39, nº 1, p. 27 a 55.

IBGE, 2008, Instituto Brasileiro de Geografia e Estatística. Matriz insumo-produto: Brasil 2000/2005. Coordenação de Contas Nacionais. Rio de Janeiro: IBGE.

KEMP, M. C. 1969, The Pure Theory of International Trade and Investment, cap. 3, Prentice-Hal Inc, New Jersey. 
LEAMER, E. 1987, Paths of development in the three-factor, N-good General Equilibrium Model, Journal of Political Economy, vol. 95, nº 5, p. 961 - 999.

LEONTIEF, W. 1953, Domestic production and foreign trade: The American capital position re-examined, Vol. 7, n ${ }^{\circ}$ 1, Economia Internazionale. In: Caves, E. R; Johnson, H. G. 1968, Readings in International Economics. Illinois: Homewood.

LONDERO, E. e S. TEITEL 1992, Industrialización, exportaciones de manufacturados y contenido de insumos primários. Trabalho apresentado no XI Encontro Latino-Americano da Sociedade Econométrica, realizado na Cidade do México, set. 1992, Resumo publicado na Revista Estudios Económicos, México, p. 121, set, 1992.

LONDERO, E. 1994, Preparing Relative Intensity Triangles. Working Paper Series 198, Banco Interamericano de Desenvolvimento.

MACHADO, D. 1997, A Qualificação da Mão-de-Obra no Comércio Internacional Brasileiro:Um Teste do Teorema de Heckscher-Ohlin, Dissertação de Mestrado em Economia ganhadora do $20^{\circ}$ Prêmio BNDES de Economia, Rio de Janeiro.

ROCCA, C. A. E J. R. MENDONÇA DE BARROS 1972, Recursos humanos e estrutura do comércio exterior. Revista Estudos Econômicos, 2 (5): 89-110.

SALES, A. S. 1993, Vantagens comparativas e padrão do comércio exterior brasileiro: uma análise empírica com ênfase no modelo Heckscher-Ohlin. Dissertação de Mestrado defendida na Universidade de São Paulo, São Paulo.

SAMUELSON, P. A.1953-1954, Prices of Factors and Goods in General Equilibrium, Review of Economic Studies, 21 (1).

SOARES, F. 2002, A Liberalização Comercial e seus Impactos Alocativos na Economia Brasileira, Revista Economia Aplicada, vol. 6, n.3, pág. 485-510.

TYLER, W. , 1970, A combinação de fatores de produção nas exportações industriais do Brasil, Revista Brasileira de Economia, 24 (1), pág. 109-128.

, 1972, O comércio de manufaturados e a participação do trabalho especializado: o caso brasileiro. Revista Estudos Econômicos, 2 (5):129-54.

VANEK, J. 1963, The Natural Resource Content of United States Foreign Trade 1870-1955, MIT Press, Cambridge, Massachusetts.

VASCONCELOS, C. R. F., 2001, Análise do Padrão do Fluxo de Comércio Externo Brasileiro Sob a Ótica do Teorema de Heckscher-Ohlin: O Caso do MERCOSUL e do Comércio com o Resto do Mundo”, Revista Estudos Econômicos, Vol. 31, n. 4, pág. 615-651.

YEATS, A. 1998, Does Mercosur's trade performance raise concerns about the effects of regional trade arrangements? The World Bank Economic Review, Vol. 12, N. 1: 1-28. 